\title{
Hiểu về năng lực số của học sinh Việt Nam
}

Nguyễn Thanh Nhàn (Trường ĐH Ngoại thương) 28/06/2021 07:01

Trong thời đại kỹ thuật số, kiến thức về lĩnh vực này đang trở nên cân thiết hơn bao giờ hết và đây cũng là trụ cột quan trọng trong việc phát triển giáo dục phổ thông, đặc biệt đối với thế hệ trẻ sinh từ năm 2002 đền 2010.

Bên cạnh việc trang bị kiến thức cho học sinh, chúng ta còn cần có những biện pháp bảo vệ các em khỏi những rủi ro trực tuyến không đáng có.

Năm 2020, nước ta có hơn 68 triệu người dùng Internet, tăng $10 \%$ so với năm 2019. Trung bình một người Việt Nam dành đến 11 giờ mỗi ngày cho Internet, phương tiện truyền thông xã hội và nội dung kỹ thuật số [1]. Như vậy, có thể nói người Việt Nam đã quen và có sẵn phương tiện để tiếp cận thông tin và các nền tảng kết nối. Mặt khác, điều này có thể tạo ra nhiều rủi ro trực tuyến. Thế nhưng, các nội dung liên quan đến an toàn kỹ thuật số hầu như không có trong các chương trình Công nghệ thông tin chính thức tại các trường học của Việt Nam. Đây cũng là môn học tự chọn trong chương trình giáo dục và không bắt buộc ở tất cả các cấp tiểu học, THCS, và THPT.

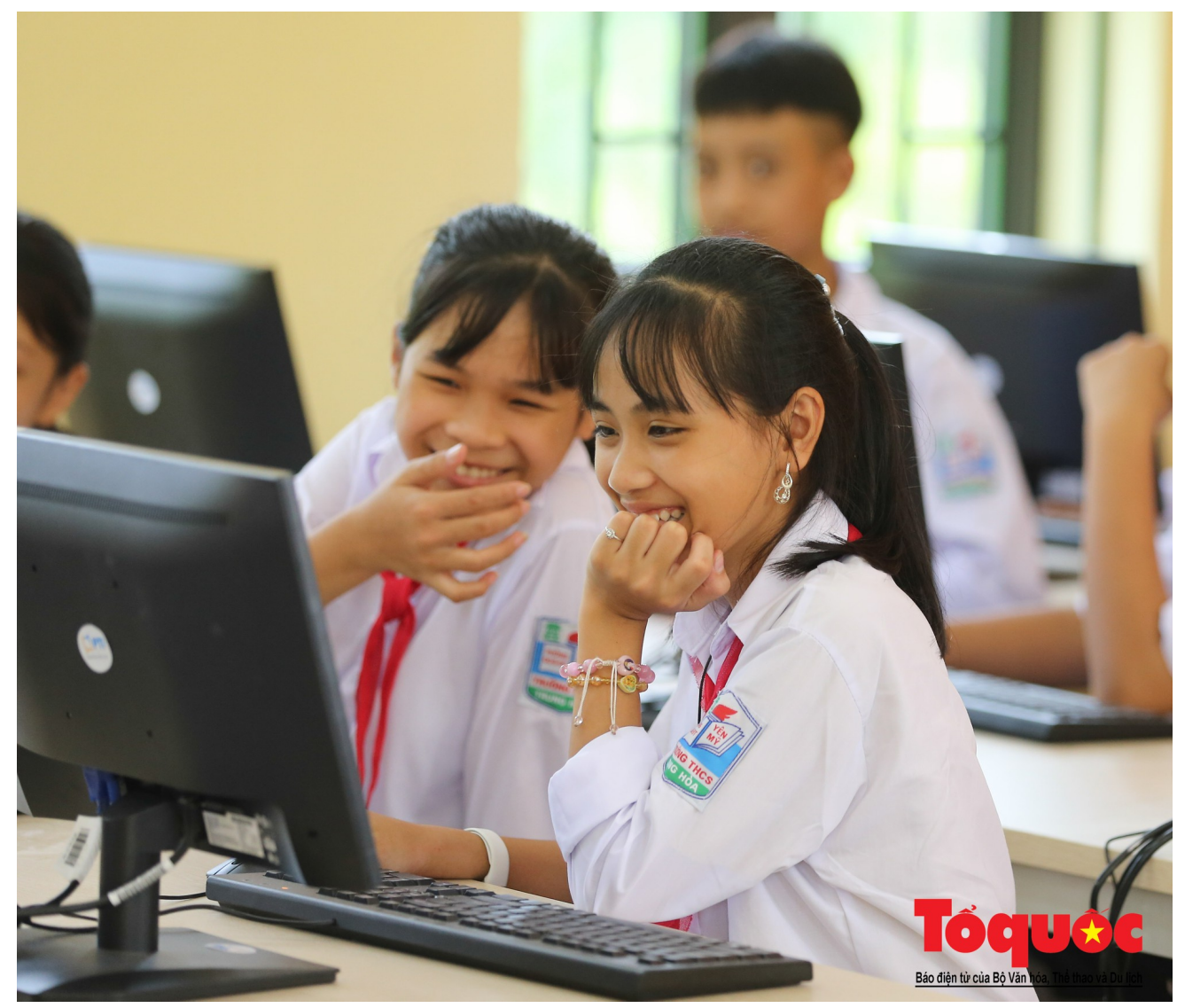


Theo nghiên cứu, các em gái có khả năng đọc viết kỹ thuật số cao hơn các em trai. Trong ảnh: Phòng học máy tính có kết nối internet ở Trường THCS Trung Hòa, xã Yên Mỹ, tỉnh Hưng Yên do Tổng công ty CP Bảo hiểm Bưu điện (PTI) cùng Quỹ văn hóa Kim Jun Ki (Hàn Quốc) tặng.

Nguồn: toquoc.vn

Trong bối cảnh đó, đã xuất hiện một số nghiên cứu tìm hiểu về năng lực số của học sinh Việt Nam và đề xuất những việc cần quan tâm để chuẩn bị một nền tảng tốt cho các em bước vào kỷ nguyên kỹ thuật số.

Thí dụ, nghiên cứu "How Digital Natives Learn and Thrive in the Digital Age: Evidence from an Emerging Economy" [2] tập trung điều tra mối liên hệ giữa trình độ kỹ thuật số của học sinh với tình trạng kinh tế xã hội của gia đình, giới tính...,

Dựa trên bộ dữ liệu mở về 1.061 học sinh lớp 10 (15 tuổi) tham gia dự án "Digital Kids Asia Pacific (DKAP)" của UNESCO, nghiên cứu này chỉ ra, gia đình có cha mẹ có trình độ học vấn và có điều kiện về kinh tế thì con cái có nhiều điều kiện và cơ hội để phát triển khả năng kỹ thuật số hơn. Cha mẹ giỏi kỹ thuật sỗ có thể hướng dẫn con cái họ sử dụng máy tính, ngoài ra họ có thể khuyến khích con cái khám phá Internet hoặc phần mềm như PowerPoint để trình bày bài tập.

Về mặt giới tính, các em gái có khả năng đọc viết kỹ thuật số cao hơn và đặc biệt là khả năng phục hồi kỹ thuật số tốt hơn các em trai. ở đây, khả năng phục hồi kỹ thuật số được hiểu là những kỹ năng khuyến khích người trẻ nhìn vào mặt tích cực và tiêu cực của những trải nghiệm trực tuyên, xem xét những tác động của chúng và đưa ra cách đối phó để xây dựng an toàn khi sử dụng thiết bị kỹ thuật số [3]. Các em, cả trai và gái, đều cần được giúp đỡ để phát triển các kỹ năng kỹ thuật số tốt hơn và tự bảo vệ mình khỏi các rủi ro trực tuyến như: các website có nội dung không lành mạnh, bị quây rối bởi các đối tượng ẩn danh, thông tin cá nhân bị lưu trữ bất hợp pháp hay bôi nhọ. Do các công nghệ sỗ sẽ tiếp tục phát triển mạnh mẽ trong tương lai với tốc độ nhanh chóng, tình trạng bất bình đẳng giới trong kỹ thuật số rất dễ xảy ra ở các nước kém phát triển. Vì vậy, cần có sự đánh giá cẩn thận và liên tục của các cơ quan chức năng để tạo ra một xã hội số hóa, cân bằng.

Về vị trí trường học, địa điểm trường học không ảnh hưởng tới kiến thức kỹ thuật số của học sinh. Sự phổ biến rộng rãi của Internet có thể là một yếu tố góp phần tạo nên điều này vì học sinh từ hầu hết mọi nơi trên đất nước Việt Nam đều có thể tiếp cận kiến thức thông qua các nền tảng trực tuyến. Đây cũng là tín hiệu tốt để các em có thể phát triển trong xu thế toàn cầu hóa đang diễn ra.

Về khả năng phục hồi kỹ thuật số, kết quả cho thãy trình độ hiểu biết về kỹ thuật số của học sinh càng cao thì khả năng hồi phục kỹ thuật số của học sinh càng cao. Các tác giả chỉ ra, tình trạng kinh tế xã hội và trình độ học vấn của phụ huynh cũng liên quan tích cực đến khả năng phục hồi kỹ thuật số của học sinh. Hơn thế nữa, việc giao tiếp giữa cha mẹ và con cái vô cùng 
quan trọng. Khi cha mẹ trò chuyện và dành thời gian cho con thì con cái cũng sẽ tiếp thu được các bài học từ cha mẹ để giải quyết các vấn đề xã hội.

Ngoài sự giúp đỡ từ cha mẹ, các em còn có thể tự bảo vệ mình bằng cách nhận thức và cảnh giác trước những mối nguy hiểm trên mạng. Để làm được điều này, các em cần được trang bị một nền tảng, kiến thức kỹ thuật số vững chắc. Do đó đâuu tư vào giáo dục Công nghệ thông tin, giúp các em nhận biết và phòng tránh rủi ro, là việc vô cùng cân thiết.

Cũng bàn về vấn đề hướng dẫn học sinh, sinh viên tôn trọng bản quyền và sử dụng nguồn tài liệu số một cách đúng đắn, hợp lý, trong một nghiên cứu có tiêu đề "Factors Affecting on the Digital Piracy Behavior: An Empirical Study in Vietnam" [4], các tác giả đã đề xuất mấy hướng như sau: nâng cao nghĩa vụ đạo đức của người dùng Việt Nam; sử dụng các công nghệ ngăn chặn như phương pháp bảo mật, mã hóa để ngăn chặn tin tặc hoặc bẻ khóa; tăng nhận thức về rủi ro vi phạm bản quyền kỹ thuật số; nâng cao quy định công nhận quyền sở hữu trí tuệ của công dân: giáo dục và thông báo cho người dân về các quy định về sở hữu trí tuệ; sử dụng phim ảnh hoặc các phương tiện thông tin đại chúng để nâng cao nhận thức của người dân về hậu quả của vi phạm bản quyền kỹ thuật số; điều chỉnh các quy định hiện hành để áp dụng hơn và hình phạt nặng hơn; khuyến khích sử dụng phần mềm miễn phí / mã nguồn mở và giảm giá các sản phẩm kỹ thuật số.

Các nhà nghiên cứu cũng lưu ý rằng, mặc dù chúng ta đang sống trong thời đại công nghệ đổi mới liên tục, nhưng trường học không nên chạy theo các xu hướng công nghệ, chẳng hạn như tìm cách ứng dụng các công nghệ kỹ thuật số phi giáo dục vào các mục đích giáo dục; mà thay vào đó, nên đóng vai trò căn bản trong việc giúp học sinh, sinh viên hình thành nhận thức về những hiện thực công nghệ-xã hội mới. Trong nghiên cứu "The university in a world of digital technologies: Tensions and challenges" [5], tác giả lập luận rằng, trong khi công nghệ kỹ thuật số dạy chúng ta những bài học mới về bản thân và tái tạo lại hiểu biết của chúng ta về năng lực con người, các trường đại học cần chuyển đổi nền giáo dục để phản ánh được sự thay đổi này. Cũng theo tác giả, đối mặt với một tương lai không chắc chắn của tự động hóa và nền kinh tế chia sẻ, các trường đại học nên thoát khỏi mô hình đào tạo sinh viên 'sẵn sàng làm việc' sau khi tốt nghiệp. Thay vì cố gắng cung cấp cho sinh viên những kiến thức và chuyên môn mang tính "đổi mới công nghệ", trường đại học nên đào tạo cho sinh viên tính linh hoạt và khả năng tự xây dựng bộ kỹ năng của riêng mình để có thể thích ứng với bản chất thường xuyên thay đổi của các công việc trong tương lai.

\section{Tài liệu tham khảo:}

1. Thanh, H. (2020). Bộ trưởng Phùng Xuân Nhạ: Nâng cao kỹ năng số cho học sinh từ cấp học đầu tiên. Vietnamnet. Retrieved 30 May 2021, from https://vietnamnet.vn/vn/giao-duc/nguoithay/nang-cao-ky-nang-so-cua-hoc-sinh-phai-la-uu-tien-hang-dau-ngay-tu-cap-hoc-dautien-681361.html

2. Tran, T., et al. (2020). How digital natives learn and thrive in the digital age: Evidence from an emerging economy. Sustainability, 12(9), 3819, DOI: 10.3390/su12093819. 
3. Do, H. V., Dorner, D. G., \& Calvert, P. (2019). Discovering the contextual factors for digital library education in Vietnam. Global Knowledge, Memory and Communication. doi: 10.1108/gkmc-08-2018-0071

4. Pham, Q. T., Dang, N. M., \& Nguyen, D. T. (2020). Factors Affecting on the Digital Piracy Behavior: An Empirical Study in Vietnam. Journal of Theoretical and Applied Electronic Commerce Research, 15(2), 0-0. doi:10.4067/s0718-18762020000200108

5. Nguyen, D. (2018). The university in a world of digital technologies: Tensions and challenges. Australasian Marketing Journal (AMJ), 26(2), 79-82. doi:10.1016/j.ausmj.2018.05.012 